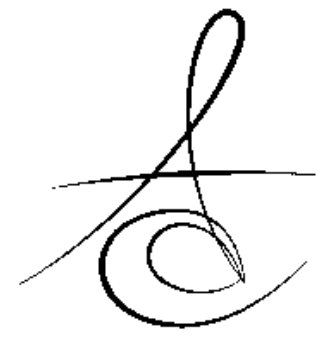

Makale Kodu/Article code: 3117

Makale Gönderilme tarihi: 07.11.2016

Kabul Tarihi: 10.01.2017

\section{DİŞ HEKİMLİĞİNDE ADEZİV SİSTEMLER}

\section{ADHESIVE SYSTEMS in DENTISTRY}

Doç. Dr. Buket AYNA*

\section{öz}

Buonocore' un asitle pürüzlendirme yöntemiyle mineye adezyonu tanımlamasından bu yana araştırmacılar yeni yöntemler geliştirmeyi amaçlamışlardır. Adeziv sistemler sürekli gelişim kaydettiğinden sınıflandırmaları da değişim göstermektedir. Adeziv sistemlerdeki gelişmeler hala devam etmekle birlikte diş hekimlerinin bu gelişmeleri düzenli takip ederek uygun materyali tercih etmeleri gerekmektedir. Böylece restorasyonun klinik başarı oranı ve hasta memnuniyeti de artacaktır. Bu derleme, adeziv sistemlerin başlangıcından günümüze kadar tarihsel gelişimi ve klinik uygulama aşamalarının sayısına ve dentin ile etkileşimlerine göre sınıflandırılmasını içermektedir.

Anahtar Kelimeler: Adezyon, self-etch adeziv, totaletch adeziv

\section{GİRIş}

Adezyon, farklı iki yüzeyin fiziksel veya kimyasal bağlanma ile bir arada tutulduğu durum olarak tanımlanmaktadır. Restoratif uygulamalarda adezyon iki farklı yüzeyden oluşan mineralize diş yapıları ve dolgu maddeleri arasında gerçekleşmektedir ${ }^{1,2}$. Adeziv sistemler rezin esaslı materyallerin dişe adaptasyonunda oldukça önemli rol oynamaktadır. Bu nedenle üreticiler iyi bir adaptasyon için ideal adeziv sistemi ve adeziv tekniği bulmaya çalışmaktadır ${ }^{3}$. Dental adezivlerin sınıflandırılmasına ilişkin literatürde farklı sınıflandırmalar mevcuttur.

Adeziv sistemler var olan smear tabakasına etkisine göre,

- Adeziv sistemler var olan smear tabakasına etkisine göre,

\section{ABSTRACT}

Since Buonocore described the adhesion of enamel with acid etching method, researchers aimed to develop new methods. Because adhesive systems show continuous improvement, they are classified in various ways. With many developments of adhesive systems, dentists follow these developments regularly and choose suitable materials. Thus the clinical success of the restoration and patient satisfaction will also increase. This review includes the historical development and classification of adhesive systems according to the number of clinical application steps and interactions with dentin.

Key Words: Adhesion, self-etch adhesive, total-etch adhesive

- Smear tabakasının üzerine uygulanan adeziv sistemler

- Smear tabakasını modifiye eden adeziv sistemler

- Smear tabakasını ortadan kaldıran adeziv sistemler

- Smear tabakasını çözen adeziv sistemler, olarak sınıflandırılmaktadır ${ }^{4,5}$.

Adeziv sistemler tarihsel gelişimlerine ve bağlanma dayanıklılılarına göre ise 7 grup olarak sınıflandırılmaktadır.

Birinci Nesil Adeziv Sistemler: 1962 yllında üretilen NPG-GMA kökenli adezivler hidroksiapatit kristallerine iyonik, kollajene ise kovalent bağlarla tutunurlar. Hidrofobik oldukları için bağlanma dayanıklılıkları (1-3 MPa) oldukça düşüktür4.

İkinci Nesil Adeziv Sistemler: 1978 yılında bisfenol-A glisidil metakrilat (bis-GMA) veya hidroksietil metakrilat (HEMA) gibi rezinlere halofosfat esterleri

\footnotetext{
${ }^{*}$ Dicle Üniversitesi, Diş Hekimliği Fakültesi, Çocuk Diş Hekimliği AD, Diyarbakır
} 
karıştırılarak klinik kullanıma sunulmuştur. Hidroksiapatit kristallerindeki pozitif yüklü kalsiyum iyonları ile rezindeki negatif yüklü fosfat grupları arasında iyonik etkileşim oluşturarak bağlanmayı gerçekleştirirler. Ortalama bağlanma dayanıklılıklarının 1-10 MPa olduğu bildirilmektedir ${ }^{6,7}$.

Birinci ve ikinci nesil adeziv sistemler smear tabakası üzerine uygulanarak dentinin inorganik yapısına bağlanma amacıyla geliştirildiğinden istenilen başarı elde edilememiştir ${ }^{4,6,7}$.

Üçüncü Nesil Adeziv Sistemler: 1984 yılında geliştirilen üçüncü nesil adezivlerde smear tabakası modifiye edilerek rezinin dentine penetrasyonunun sağlanması amaçlanmıştır. Bu sistem hem hidrofilik hem hidrofobik monomer olan 4-META'dan (4-metakriloksietil trimellitat anhidrit) oluşmaktadır. Bağlanma dayanımı yaklaşık 10-14 MPa olarak bildirilmektedir ${ }^{7,8}$.

Dördüncü Nesil Adeziv Sistemler: 1990'ların başında geliştirilen ve smear tabakasını tamamen uzaklaştırmayı amaçlayan dördüncü nesil adeziv sistemin temel özelliğini etch and rinse tekniği oluşturmaktadır. Bu teknik ile hem mine hem de dentin fosforik asit ile pürüzlendirilerek yıkanıp hafifçe kurutulmaktadır. Kollajen yıkımını önlemek amacıyla yüzeylerin nemli kalması önemlidir. Daha sonra hidrofilik bir primer ve son olarak doldurucusuz bir bonding ajan uygulanmaktadır. Ortalama bağlanma dayanımının 1830 MPa olduğu bildirilmektedir ${ }^{9,10}$.

Beşinci Nesil Adeziv Sistemler. 1990'ların ortalarında geliştirilen ve yine smear tabakasını tamamen uzaklaştırmayı amaçlayan beşinci nesil adeziv sistemler üç aşamalı etch and rinse adeziv sistemi daha basit hale getirmek amacıyla primer ve adeziv rezinin birleştirildiği "one bottle" sistem olarak adlandırılan adezivlerdir. Bağlanma dayanıklıı̆ının dördüncü nesil adeziv sistemlere benzediği iddia edilmektedir $^{10,11}$.

Altıncı Nesil Adeziv Sistemler: 2000'li yılların başında geliştirilen ve smear tabakasını tamamen kaldırmadan sadece çözmeyi hedefleyen bu sistemde; asitle pürüzlendirme, yıkama ve kurutma işlemleri elimine edilmiştir. Sistem asidik primer ve adeziv rezin uygulamasını içermektedir. Bağlanma dayanımları dentinde yeterli bulunsa da minede daha zayıf olduğu bildirilmektedir ${ }^{12}$.

Yedinci Nesil Adeziv Sistemler: 2000'li yılların sonlarında geliştirilen yedinci nesil adezivler yine smear tabakasını çözmeyi hedefleyerek ve teknik hassasiyeti azaltmayı amaçlayarak geliştirilmiştir. Asidik monomer, primer ve bonding ajan tek şişede birleştirilerek "All in One" sistemler olarak piyasaya sürülmüştür ${ }^{12,13}$. Son yıllarda "All in One" sistemlerin dezavantajlarını ortadan kaldırmak amacıyla sunulan "Universal" veya "Multimode" olarak adlandırılan ürünler de yedinci nesil adezivler olarak sınıflandırılmaktadır. Bağlanma dayanımlarının altıncı nesil adezivlere benzer olduğu iddia edilmektedir ${ }^{14}$.

Araştırmacılar adeziv sistemler için var olan tarihsel gelişim sınıflamasının bilimsel temellere dayalı olmadığını ifade etmiştir. Bu nedenle adeziv sistemlerin uygulama yöntemleri ve dentin ile etkileşimlerine göre sınıflandırılmasının daha basit ve güvenilir olduğu düşünülmektedir ${ }^{15-17}$.

$\mathrm{Bu}$ bilgilerin ışı̆ı altında adeziv sistemler uygulama yöntemlerine göre sınıflandırıldığında üç başlık altında incelenmektedir ${ }^{1,2,4,17}$.

1. Etch and Rinse Adeziv Sistemler

a) Üç Aşamalı (4. Jenerasyon)

b) İki Aşamalı (5. Jenerasyon)

2. Self Etch Adeziv Sistemler
a) İki Aşamalı (6. Jenerasyon)
b) Tek Aşamalı (7. Jenerasyon)

3. Cam İyonomer Adeziv Sistemler

\section{ETCH AND RINSE (ER) ADEZİV SİSTEMLER} 1955 yılında Buonocore' un \%85' lik fosforik asitle pürüzlendirme yöntemiyle mineye adezyonu tanımlamasından bu yana adeziv sistemlerde asitle pürüzlendirme işlemi altın standart olarak kabul edilmektedir $^{18,19}$.

ER adeziv sistemler, öncelikle \%30-40' lık fosforik asitle hem mine hem dentinde pürüzlendirme uygulamasını içermektedir ${ }^{17,20}$. Minede hidroksiapatitler uzaklaştırılıp derin boşluklar elde edilirken, dentinde birkaç mikrometrelik demineralize alanlar oluşturularak kollajenler açığa çıkarılmaktadır ${ }^{21}$. ER adeziv sistemler kullanımlarına göre, asitle pürüzlendirme, primer ve adeziv rezin uygulanmasını içeren üç aşamalı sistem ve primer ve adezivin tek şişede birleştirildiği iki aşamalı (one bottle) sistem olarak iki sınıfta incelenmektedir ${ }^{20-22}$.

\section{a) Üç Aşamalı ER Adeziv Sistemler}

ER adeziv sistemlerde asitle pürüzlendirme aşaması ile minenin yüzey alanı ve yüzey enerjisini arttırmak amaçlanmaktadır ${ }^{23}$. Asitle pürüzlendirme 
işleminde, uygulanan asidin konsantrasyonu, formu (solüsyon, jel, semijel), uygulama süresi, yöntemi, diş dokusunun mineral içeriği ve geçirgenlik düzeyi önemlidir ${ }^{24,25}$. Minenin pürüzlendirilmesiyle 5-50 $\mu \mathrm{m}$ derinliğinde pöröz bir tabaka oluşturulduğu ve iyi sonuçlar elde edildiği bildirilmektedir. Semijel formu mine yüzeyini daha iyi ıslatmaktadır ve içerdiği benzalkonyum klorid antimikrobial etkilidir ${ }^{4,26,27}$. Asitin minede meydana getirdiği mikropöröz alanlara rezin monomerlerinin infiltrasyonu ve polimerizasyonuyla mikromekanik bağlanma oluşmaktadır ${ }^{19}$. Mine asitlendikten sonra mine prizmaları arasında oluşan boşluklara rezin infiltrasyonuyla oluşan rezin taglar macrotag, prizma iç kısımlarında oluşan rezin taglar ise microtag olarak adlandırımaktadır ${ }^{28}$.

Dentin, diş pulpasını koruyan, dişin büyük bir kısmını oluşturan, dentin tübüllerini içeren kompleks bir yapıdır ${ }^{29}$. Diş kesimi sonrası dentin yüzeyinde oluşan debris smear tabakası olarak adlandırımaktadır. Adezyon için smear tabakasının kaldırıması, modifiye edilmesi ya da çözülmesi gerektiği düşünülmektedir ${ }^{30}$. Dentin dokusuna uygulanan asit hidroksiapatit kristallerini çözerek dentin yüzeyinden uzaklaştırmaktadır. Kollajen fibriller arası boşluk yaklaşık $30 \pm 11$ nm'dir. Bu boşluklar, kollajen matriksin demineralize tabakasında yaklaşık $5 \mu \mathrm{m}$ derinlikte adeziv monomerlerinin infiltre olabileceği kanallar olarak görev yapmaktadır $^{31}$. ER adeziv sistemlerde asit uygulamasıyla smear tabakasını kaldırmak, dentin tübüllerini açmak, demineralizasyona bağlı kollajen fibrilleri açığa çıkarmak, sonrasında uygulanan primer ve bonding ajanla hibrit tabakası oluşturulmak amaçlanmaktadır ${ }^{32}$.

Üç aşamalı ER adeziv sistemde asit uygulanması ve yıkanmasının ardından nemli bırakılan dentin yüzeyine primer uygulanmaktadır ${ }^{33}$. Minede iyi bir bağlanma sağlanabilmesi için hava ile kurutma işlemi gerekirken demineralize dentinin kurutulması sırasında kollajen fibrillerin büzülme riski bulunduğundan dentini nemli tutmak oldukça önemlidir. Bu teknik "wet bonding" ya da "nemli bağlanma" olarak tanımlanmaktadır. Yüzeyin nemli bırakılmasıyla kollajen lifler arası boşluklar suyla desteklenir ve liflerin büzülmesi önlenmiş olur. Asit uygulaması sonucu açığa çıkan yüksek protein içeriği dentinin kritik yüzey gerilim değerinin düşmesine, dolayısıyla dentin yüzeyinin ıslatılamamasına ve bağlanmanın zorlaşmasına sebep olmaktadır. İkinci aşama olarak uygulanan primer demineralize dentin alanının, kritik yüzey gerilim değerini arttırmaktadır ${ }^{19,34}$.

Primerler su, aseton, etanol gibi organik çözücü içinde hidrofilik monomer içermektedir. Asitlenmiş dentine uygulanan primerler kollajen ağındaki su ile yer değiştirerek monomerin infiltrayonunu kolaylaştırmaktadır ${ }^{34}$. Böylece hibrit tabakanın kalitesi ve bağlanma dayanıklıı̆ı̆ artmaktadır. Primer içinde bulunan rezinlerden HEMA (2-hydroxyethyl methacrylate) hidrofilik ve hidrofobik olmak üzere iki fonksiyonel grup içermektedir. Hidrofilik grup dentin yüzeyine tutunma eğilimi taşırken, hidrofobik grup kompozit rezine tutunma eğilimindedir ${ }^{17}$. HEMA moleküler ağırlığının düşük olması ve hidrofilik özelliği nedeni ile Islatma yeteneği oldukça iyi bir monomerdir ${ }^{35}$. HEMA'dan başka N-toliglisinglisidil metakrilat (NTG-GMA), bisfenildimetakrilat (BPDM), piromellitik asit dietil metakrilat (PMDM), dipenta eritrol pentaakrilat monofosfat (PENTA), 4 metakriloksietil trimelliat anhidrid (4META) gibi monomerler de primer olarak kullanılmaktadır. Kısacası primerler, kimyasal yapıları farklı olan dentin ile rezini uyumlu hale getirmektedir ${ }^{4,35}$.

Ardından bonding ajan olarak tanımlanan adeziv rezin primer uygulanmış dentine sürülmektedir. Bonding ajanlar Bis-GMA (bisphenylglycidyl dimethacrylate), TEG-DMA (triethylene glycol dimethacrylate), UDMA (urethane dimethacrylate) gibi düşük visköziteli hidrofobik monomerlerden oluşmaktadır ve zayıf infiltrasyonla sonuçlanmaktadır ${ }^{4,36}$. Adeziv sistemlere infiltrasyonu arttırmak amacıyla HEMA gibi hidrofilik monomerler eklenmektedir. Etkili bir bonding ajanın dentine yeterince infiltre olabilmesi için hidrofilik gruplar ve Bis-GMA gibi monomerler, kopolimerizasyonu için hidrofobik gruplar içermesi gerekmektedir $^{37,38}$.

Bonding ajanın intertübüler dentine penetrasyonu ve polimerizasyonuyla tübüler rezin tag oluşumu ve hibrit tabakanın sabitlenmesi sağlanmaktadır. Primer uygulandıktan sonra oluşan hibrit tabaka bağlayıcı ajan ile polimerize olmaktadır ${ }^{26}$. Mevcut üç aşamalı ER adeziv sistemlerden bazı örnekler Tablo 1 'de gösterilmektedir.

Bu teknikte dentinin aşırı derecede asitlenmesi ya da yıkama işlemi sonrası dentinin aşırı derecede kurutulması bağlanmanın zayıf olmasına sebep olmaktadır. Bunun yanında nem kontrolünün zorluğu ve uygulama basamaklarının fazla olması hata yapma olasılığını arttırmaktadır ${ }^{17}$. Bu yüzden üç aşamalı ER adeziv sistemlerde yetersiz rezin infiltrasyonu, yetersiz 
hibridizasyon, hidrolitik bozulma, desteksiz kollajenler ve postoperatif hassasiyet görülebilmektedir ${ }^{39,40}$. Su veya solventlerin de yüzeyden tam olarak uzaklaştırılamaması hidrolitik bozulmaya sebep olmaktadı ${ }^{41}$. Ayrıca derin kavitelerde pulpanın kaide materyali ile korunmadığı durumlarda asit uygulaması irreversibl pulpitise neden olmaktadır ${ }^{42}$. Bu nedenle üreticiler üç aşamalı ER adeziv sistemleri basitleştirmeye yönelmişler ve iki aşamalı ER adeziv sistemi geliştirmişlerdir ${ }^{43}$.

Tablo 1. Üç aşamalı ER adeziv sistemlerden bazı örnekler

\begin{tabular}{|l|l|}
\hline \multicolumn{1}{|c|}{ ÜÇ AŞAMALI ER ADEZİV } & \multicolumn{1}{c|}{ ÜRETI } \\
SİSTEMLER & Ci FİRMA \\
\hline Adper Scotcbond Multi-Purose & 3M ESPE \\
\hline Scotcbond Multi-Purose & 3 M ESPE \\
\hline All Bond 2 & Bisco \\
\hline All Bond 3 & Bisco \\
\hline Bond-It & Pentron \\
\hline Denthesive & Hereaus- Kulzer \\
\hline EBS & 3M ESPE \\
\hline Gluma Solid Bond & Hereaus- Kulzer \\
\hline Optibond FL & Kerr \\
\hline Paama 2 & SDI \\
\hline Permagen & Ultradent \\
\hline Permaquik & Ultradent \\
\hline Probond & Dentsply \\
\hline Solobond Plus & Voco \\
\hline Syntac & IvoclarVivadent \\
\hline Tenure Multi Purpose & Den-Mat \\
\hline
\end{tabular}

\section{b) İki Aşamalı ER Adeziv Sistemler}

İki aşamalı ER sistemde, asit ile pürüzlendirme üç aşamalı sistemde olduğu gibi ilk aşamayı oluşturmaktadır. Hidrofobik bonding ajan ile hidrofilik ve solvent içeren primerin tek bir solüsyonda birleştirildiği "one bottle" olarak adlandırılan adeziv sistemlerdir ${ }^{44,45}$. Bağlanma mekanizması üç aşamalı ER sistemler ile aynıdır. Bu sistemde de nemli bağlanma şarttır. Amaç işlem sayısını azaltarak teknik hassasiyeti azaltmak olsa da, ikinci aşamanın birkaç kez uygulanmasının önerilmesi sürenin uzamasına neden olmaktadır. Bunun yanında asit uygulanan dentin üzerine primer ve bonding ajanın birlikte uygulanması dentinin iyi örtülenmesini ve hibridizasyonun etkinliğini azaltabilmektedir. Ayrıca polimerizasyon büzülmesinin fazla olduğu durumlarda postoperatif hassasiyet riski artmaktadır ${ }^{7} 46$. Mevcut iki aşamalı ER adeziv sistemlerden bazı örnekler Tablo 2'de gösterilmektedir.

\section{SELF ETCH (SE) ADEZİV SİSTEMLER}

ER adeziv sistemler ile ilgili devam eden problemler SE adeziv sistemlerin gelişmesine neden olmuştur. Smear tabakasının dentin ve pulpa dokusunu irritasyonlara karşı koruduğu görüşünden hareketle smear tabakasını içeren bir hibrit tabakanın elde edilmesi amaçlanmıştır ${ }^{47}$. Asitleme ve yıkama işlemleri elimine edilerek asidik monomer ile mine ve dentini eş zamanlı demineralize etmesi söz konusudur.

SE adezivler dentin dokusuyla etkileşim derecelerine göre;

* Kuvvetli SE Adezivler $(\mathrm{Ph} \leq 1)$

* Orta Derece Kuvvetli SE Adezivler $(\mathrm{Ph} \approx 1,5)$

* Hafif Etkili SE Adezivler $(\mathrm{Ph} \geq 2)$

* Zayif Etkili SE Adezivler $(\mathrm{Ph} \geq 2,5)$ olarak sınıflandırılmaktadır ${ }^{48}$.

Tablo 2. İki aşamalı ER adeziv sistemlerden bazı örnekler

\begin{tabular}{|l|l|}
\hline İKI AŞAMALI ER ADEZIV SİSTEMLER & ÜRETÍCI FİRMA \\
\hline Admira Bond & Voco \\
\hline Adper Single Bond 2 & 3 M ESPE \\
\hline Bond-1 & Pentron \\
\hline Clearfil New Bond & Kuraray \\
\hline Clearfil Photo Bond & Kuraray \\
\hline Excite & IvoclarVivadent \\
\hline Excite DSC & IvoclarVivadent \\
\hline Gluma Comfort Bond & Heraeus-Kulzer \\
\hline Gluma 2 Bond & Heraeus-Kulzer \\
\hline One Coat Bond & Coltane/Whaledent \\
\hline One Step & Bisco \\
\hline One Step Plus & Bisco \\
\hline Optibond Solo Plus & Kerr \\
\hline Optibond Solo Plus Dual-Cure & Kerr \\
\hline Prime\&Bond NT & Dentsply \\
\hline Prime\&Bond NT Dual-Cure & Dentsply \\
\hline Solobond M & Voco \\
\hline Stae & SDI \\
\hline Teco & Zenith/DMG \\
\hline Tenure Quik & Den-Mat \\
\hline Te-Econom & Ivoclar-Vivadent \\
\hline XP Bond & Dentsply \\
\hline
\end{tabular}

Kuvvetli SE adeziv sistemler: Oldukça derin demineralizasyon sağlamaktadırlar ve ER adeziv sistemlere benzer bağlanma mekanizmasına sahip- tirler. Dentinde kollajen fibrilleri açığa çıkararak neredeyse tüm hidroksiapatit kristallerini çözerler. Dentin infiltrasyonu derindir. Bu nedenle oluşan hibrit tabakası kalındir ve rezin taglar mevcuttur ${ }^{40}$. Oluşan hibrit tabaka ER adeziv sistemlerde oluşan hibrit tabakaya çok benzer$\mathrm{dir}^{34}$. Mineye bağlanmaları da kabul edilir düzeydedir. Ancak demineralizasyon aşamasını başlatmak amacıyla daha yüksek oranda su içermektedirler. Bu durumda su dentin yüzeyinden tamamen uzaklaştıılamadığı için polimerizasyon sırasında açığa çıkan fazla su bağlanmayı olumsuz etkilemekte ve sızıntı riskini arttırmaktadır $^{49,50}$.

Orta derece kuvvetli SE adeziv sistemler: Dentinde yeterli demineralizasyon sağlarlar. En önemli avantajları kollajen fibrilleri hidroksiapatit kristallerinin etrafında tutmalarıdır. Böylelikle demineralize dentinde

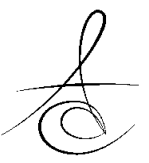


kollajenler arası hidroksiapatit kristallerindeki kalsiyum iyonu ile SE adeziv sistemlerin içerdiği karboksilik asit veya fosforik asit monomerleri arasında kimyasal etkileşim olmaktadır. Bu özellik hem mikromekanik hem de kimyasal bağlanma ile restorasyonun dayanıkIılığı açısından avantaj sağlar ve kollajenleri hidrolize karşı koruyarak bağlanmanın erken bozulmasının önüne geçer. Mine dokusuna dentin dokusu kadar iyi bir bağlanma sağladığı bildirilmektedir ${ }^{51-54}$.

Hafif etkili SE adeziv sistemler: Smear tabakası hibrit tabaka içinde yer almaktadır. Böylece rezin monomerlerinin pulpadan gelen SIVı hareketiyle çözünmesi önlenmeye çalışılmaktadır. Bu sistemle dentin oldukça yüzeyel demineralize edilerek kimyasal etkileşim için kollajen fibrillerin etrafında hidroksiapatitin kalmasına izin verilmektedir ${ }^{55,56}$. Bu olay bağlanmanın erken dönemde bozulmasını önlese de monomer infiltrasyon derinliğinin $1 \mu \mathrm{m}$ 'den az olması ve yetersiz rezin penetrasyonu ilerleyen dönemlerde nanosızıntıya sebep olabilmektedir. Mine dokusunda tam bir pürüzlendirme gerçekleşmediği için minede bizotaj işlemi önerilmektedir ${ }^{51,53}$.

Zayıf etkili SE adeziv sistemler: Hem mine hem de dentin dokusu ile yüzeyel bir etkileşim gerçekleşmektedir. Dentinde kollajen fibriller açığa çıkmazken, hibrit tabaka kalınlığının yaklaşık 0,2 $\mu \mathrm{m}$ olduğu bildirilmektedir ${ }^{49,52,56}$. Asiditelerine göre adeziv sistemlerden bazı örnekler Tablo 3'de gösterilmektedir.

Tablo 3. Asiditelerine göre adeziv sistemlerden bazı örnekler

\begin{tabular}{|l|l|}
\hline ASİDİTELERİNE GÖRE ADEZIV SISTEMLER & pH \\
\hline Nano Bond & $\mathrm{PH}=1.2$ \\
\hline Prompt L-Pop2 & $\mathrm{PH}=0.8$ \\
\hline Clearfil SE Bond & $\mathrm{PH}=1.9$ \\
\hline UnifillBond & $\mathrm{PH}=2.2$ \\
\hline One-UpBondF & $\mathrm{PH}=2.6$ \\
\hline AQ Bond & $\mathrm{PH}=2.1$ \\
\hline Xeno IV & $\mathrm{PH}=2.5$ \\
\hline All-Bond SE & $\mathrm{PH}=2.2$ \\
\hline Xeno III & $\mathrm{PH}=1.4$ \\
\hline Optibond All in One & $\mathrm{PH}=2.5-3$ \\
\hline Futurabond NR & $\mathrm{PH}=1.4$ \\
\hline Clearfil Protect Bond & $\mathrm{PH}=1.9$ \\
\hline Clearfil S3 Bond & $\mathrm{PH}=2.7$ \\
\hline Panavia ED Mixed Primer & $\mathrm{PH}=2.6$ \\
\hline Adper Prompt L-Pop & $\mathrm{PH}=0.4$ \\
\hline Tyrian SPE & $\mathrm{PH}=0.5$ \\
\hline AdheSE & $\mathrm{PH}=1.7$ \\
\hline OptiBond Solo Plus SE & $\mathrm{PH}=1.5$ \\
\hline
\end{tabular}

SE adezivler uygulama prosedürlerine göre ise;

a) İki Aşamalı SE Adezivler

$>\quad$ Antibakteriyel SE Adezivler

b) Tek Aşamalı SE Adezivler (All in One)

> Tek Komponentli SE Adezivler $>\quad$ İki Komponentli SE Adezivler

> Tek Aşamalı Universal (Multimode) Adezivler olarak sınıflandırılmaktadır ${ }^{4,14}$.

\section{a) İki Aşamalı SE Adeziv Sistemler}

Birinci aşamayı asidik monomer ilave edilmiş hidrofilik primer solüsyonu, ikinci aşamayı ise hidrofobik bonding ajan uygulaması oluşturmaktadır. Asidik primer uygulanmış yüzeye bonding ajan uygulandıktan sonra her iki tabaka birlikte ışıkla polimerize edilir. Bu sistemlere eklenen 4-methacryloyloxyethyl trimellitic anhydride (4-META), 2- methacryloyloxyethyl phenyl hydrogen phosphate (Phenyl-P) ve 10-methacryolyloxydecyl dihydrogen phosphate (MDP) gibi fonksiyonel asidik monomerlerle açığa çıkan hidroksiapatit kristaleri ve içerdikleri kalsiyum arasında elektrostatik etkileşim oluşmaktadır ${ }^{48,57-60}$. 'Adezyon-Dekalsifikasyon' konsepti adı verilen bu etkileşime göre kalsiyummonomer kompleksinin stabilitesine bağlı olarak bu iyonik bağlanma ya diş sert dokularını demineralize etmektedir ya da kalsiyum ile kimyasal bağlanmaktadır. Böylece hibrit tabaka ile pürüzlendirilen yüzey arası boşluk minimalize edilmektedir ${ }^{49,61,62}$. İki aşamalı SE adeziv sistemlerden bazı örnekler Tablo 4'de gösterilmektedir.

Tablo 4. İki aşamalı SE adeziv sistemlerden bazı örnekler

\begin{tabular}{|l|l|}
\hline İKí ASSAMALI SE ADEZİV SİSTEMLER & ÜRETİCI FİRMA \\
\hline AdheSE & Ivoclar Vivadent \\
\hline Adper SE Plus & 3 M ESPE \\
\hline ART Bond & Coltane/Whaledent \\
\hline Clearfil Liner Bond 2V & Kuraray \\
\hline Clearfil SE Bond & Kuraray \\
\hline Clearfil Protect Bond & Kuraray \\
\hline Contax & Zenith/DMG \\
\hline Frog & SDI \\
\hline FL-Bond & Shofu \\
\hline GC Unifill Bond & GC America \\
\hline OneCoat Self Etching Bond & Coltane/Whaledent \\
\hline Tyrian SPE/ One Step Plus & Bisco \\
\hline Nano-Bond & Pentron \\
\hline Prelude SE & Danville Materials \\
\hline
\end{tabular}

Son yıllarda adeziv sistemlerdeki gelişmelere ek olarak antibakteriyel etkili adeziv sistemler geliştirilmiştir. Adeziv sistemlere antibakteriyel özellik kazandırmak için gluteraldehit gibi maddeler eklenmiştir. "Gluma, Syntac ve Probond" gibi adezivler gluteraldehit içermektedir. SE adeziv sistemler smear tabakasını tamamen ortadan kaldırmadığı için özellikle streptokokus mutans gibi rezidüel bakterilere karşı güçlü bakterisid aktiviteye sahip MDPB (methacryloyloxydodecylpyridinium bromide) monomeri içermekte olan antibakteriyel etkili SE adeziv olarak

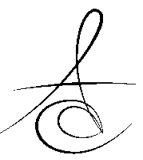


"Clearfil Protect Bond" üretilmiştir. Polimerizasyon sonrası MDPB, primer içinde sabit şekilde kalabilmektedir ve antibakteriyel etkinliği uzun dönem devam etmektedir. Dolayısıyla "Clearfil Protect Bond" un restorasyon yerleşiminden sonra bağlanma yüzeyinde oluşan boşluklara invaze olan bakterileri inhibe etmesi beklenmektedir ${ }^{63-65}$.

\section{b) Tek Aşamalı SE Adeziv Sistemler}

Klinik olarak asidik monomer, primer ve bonding ajanın bir arada bulunduğu tek aşamada uygulanan sistemlerdir. Bu tür adeziv sistemler smear tabakasını çözebilmek ve dentini demineralize edebilmek için yüksek oranda su içermektedir ${ }^{66-69}$. Bu aşırı hidrofilik özellik, polimerizasyondan sonra yarı geçirgen bir membran gibi davranıp dentinden su geçişine izin vererek hidrolitik bozulmaya neden olan su kabarcıklarını oluşturmaktadır ${ }^{70-73}$. Adeziv rezinin ışıkla sertleşmesi sırasında oluşan ISı suyun rezin tabakası boyunca kanallar halinde yayılmasına sebep olmaktadır. Mine-adeziv ve hibrit tabaka-adeziv arasında TEM' de oluşan görüntü su ağaçları (water-tree) olarak adlandırılmaktadır. Su ağaçlarının zamanla hidrolitik yıkımın başlangıç noktaları olduğu ve nanosızıntıdan sorumlu olduğu düşünülmektedir ${ }^{4,18,74}$.

Karıştırma işlemi gerektiren iki komponentli SE adeziv sistemin yerini son yıllarda karıştırma işlemi gerektirmeyen tek komponentli sistemler almıştır ${ }^{4}$. Tek aşamalı SE adeziv sistemlerden bazı örnekler Tablo 5 'de gösterilmektedir.

Tablo 5. Tek aşamalı SE adeziv sistemlerden bazı örnekler

\begin{tabular}{|l|l|}
\hline Tek Aşamalı Se Adeziv Sistemler & Üretici Firma \\
\hline $\begin{array}{l}\text { İki Komponentli SE Adeziv } \\
\text { Sistemler }\end{array}$ \\
\hline Adper Prompt L-Pop & \\
\hline All-Bond SE & 3M ESPE \\
\hline AQ Bond & Bisco \\
\hline Brush\&Bond (Hybrid Bond) & Sun Medical Co. \\
\hline Clearfil DC Bond & Parkell \\
\hline Futurabond DC & Kuraray \\
\hline Futurabond NR & Voco \\
\hline Gloss-N-Seal/Tenure Uni-Bond & Voco \\
\hline Reactmer Bond & Den-Mat \\
\hline Touch\&Bond & Shofu \\
\hline One-Up Bond F & Parkell \\
\hline Xeno III & Tokuyama Dental Corp./ USA \\
\hline Xeno IV & Dentsply/Caulk \\
\hline $\begin{array}{l}\text { Tek Komponentli SE Adeziv } \\
\text { Sistemler }\end{array}$ & Dentsply/Caulk \\
\hline AdheSE One & \\
\hline Adper Easy Bond & Ivoclar Vivadent \\
\hline Clearfil S3 Bond & 3M ESPE \\
\hline Futurabond M & Kuraray \\
\hline G-Bond & Voco \\
\hline Go! & GC America \\
\hline İBOND & SDI \\
\hline Optibond All-in-One & Heraeus Kulze \\
\hline One Coat 7.0 & Kerr Corp \\
\hline Xeno V & Coltène/Whaledent \\
\hline & Dentsply \\
\hline
\end{tabular}

Son dönemlerde klinik kulanım kolaylığı sağlayan tek aşamalı SE adeziv sistemlerin dezavantajlarını ortadan kaldırmak amacıyla "Universal" veya "Multimod" olarak adlandırılan ürünler ortaya çıkmıştır. Universal adezivlerde $\mathrm{pH} \geq 2^{\prime} \operatorname{dir}^{49,75}$. Universal adezivler hem SE hem ER adeziv sistem ile birlikte kullanılabilmesinin yanı sıra minede (selektif asitleme yapılarak) ER, dentinde SE adeziv sistem olarak da kullanılmaktadır. Universal adezivler geleneksel tek aşamalı self etch adezivlere benzer içeriğe sahiptir, hidroksiapatit içerisindeki kalsiyuma bağlanan karboksilat veya fosfat monomeri içermektedirler. Bu monomerlere ek olarak metakriololoksidesil dihidrojen fosfat (10-MDP), silan, poliakrilik asit gibi monomerler eklenmiştir. Yapılan çalışmalar, minenin selektif asitlenmesi ile Universal SE adezivlerin tek aşamalılardan daha iyi bağlanma ( $\approx 40 \mathrm{MPa})$ gösterdiğini ortaya çıkartmıştır. İçeriğindeki 10-MDP monomeri ile hem mine hem de dentinde mikromekanik bağlanmaya kimyasal bağlanma eşlik etmektedir ${ }^{17,75,76}$. Mine ve dentinde görülen mekanik ve kimyasal bağlanmanın yanında Universal adezivlerin en önemli avantajı restoratif işlem çeşitliliği ve adezyon stratejisi sağlamasıdır. Ancak Universal adezivlerin de diğer tek aşamalı SE adezivler gibi su içermesi hidrolitik yıkım oluşturmaktadır. Bu yüzden polimerize olan Universal adezivin üzerine hidrofobik bir rezin uygulaması önerilmektedir. Suyun varlığı tüm tek aşamalı adezivler için problem olduğundan etanol üzerinde çalışılmaktadır $^{14,74}$. Mevcut Universal adeziv sistemlerden bazı örnekler Tablo 6'da gösterilmektedir.

Tablo 6. Universal adeziv sistemlerden bazı örnekler
\begin{tabular}{|l|l|}
\hline UNİVERSAL ADEZIV SİSTEMLER & ÜRETİCI FİRMA \\
\hline AdheSE Universal & Ivoclar Vivadent \\
\hline All-Bond Universal & Bisco \\
\hline ClearfilUniversal Bond & Kuraray \\
\hline Futurabond U & Voco \\
\hline Prime\&Bond Elect & Dentsply \\
\hline Scotchbond Universal Adhesive & 3 M ESPE \\
\hline Prebond SE & President Dental \\
\hline Gluma Bond Universal & Heraeus Kulzer \\
\hline Single Bond Universal & $3 \mathrm{M}$ ESPE \\
\hline
\end{tabular}

\section{CAM İYONOMER ADEZIV SISTTEMLER}

Cam iyonomerler hem mine hem dentine kendinden bağlanabilen restoratif materyallerdir. Cam iyonomerlerin yapısında polialkenoik kopolimer, doldurucu cam partiküller ve su bulunmaktadır. Cam iyonomerlerin diş yüzeyine bağlanmasını arttırmak amacıyla yüzeyler polialkenoik asitle temizlenerek yıkanmaktadır $^{17,77}$. Asitleme işlemiyle 0,5 $\mu \mathrm{m}$ derinlikte 
kollajenler açı̆̆a çıkartılmaktadır. Cam iyonomer bileşenlerinin oluşan boşluklara infiltre olmasıyla mikromekanik bağlanma sağlanmaktadır. Polialkenoik asitin karboksil grupları ile hidroksiapatit kristallerindeki kalsiyum iyonu arasında kimyasal bağlanma sağlanmaktadır. Böylece diş yüzeyinde hem kimyasal hem mikromekanik bağlanma elde edilmektedir ${ }^{78,79}$.

\section{SONUÇ}

Buonocorre'un mine yüzeyine asit uygulamasıyla başlayan ve günümüze kadar pek çok gelişme kaydeden adeziv sistemlerin her biri diğerine göre avantaj ve dezavantaja sahiptir. Konu ile ilgili yapılan çalışmalar incelendiğinde;

1) ER adeziv sistemlerle elde edilen bağlanma kuvvetlerinin özellikle mineye bağlanmada SE sistemlere göre üstünlük gösterdiği bildirilmektedir.

2) Ancak SE sistemlerin kolay uygulanma, teknik hassasiyet azlığı ve uygulama zamanını kısaltması gibi avantajları mevcuttur. İki aşamalı SE adezivlerle ER adezivler ile kıyaslanabilir düzeyde başarılı sonuçlar alınmıştır. Her ne kadar tüm SE sistemler mineye bağlansa da demineralizasyonun daha yüzeyel olması klinik olarak mine kenarlarında renklenme şeklinde kendini göstermektedir.

3) Tek aşamalı SE adezivlerin hidrofilik yapıları nedeniyle geçirgen bir membran gibi davranmaları, polimerizasyon sonrası su absorbe etmeleri ve hidrolize yatkın hale gelmeleri diğer adeziv sistemlere göre daha başarısız bulunmasının nedeni olarak açıklanmaktadır.

Elmas Tüfek: $O R C I D I D: 0000-0001-6087-7590$

Buket Ayna: ORCID ID: 0000-0003-1963-8568

\section{KAYNAKLAR}

1. Çınar Ç. Çocuk Diş Hekimliğinde Adeziv Sistemlerin Tarihsel Gelişimi ve Sınıflandırılması. Turkiye Klinikleri J Dental Sci-Special Topics 2011;2:1-7.

2. Eligüzeloğlu E. Son Donem Geliştirilen Adeziv Sistemler. OMÜ Diş Heki Faki Derg 2009;10:22-29.

3. Frankenberger R, Perdigao J, Rosa BT, Lopes $M$. 'No-bottle' vs 'multi-bottle' dentin adhesives-a microtensile bond strength and morphological study. Dent Mater 2002;17:373-80.

4. Dayangaç GB. Kompozit Restorasyonlar, 2. Baskı. İstanbul; Quintessence Yayıncılık: 2011. s. 25-57.
5. Van Meerbeek B, Perdigao J, Lambrechts P, Vanherle $\mathrm{G}$. The clinical performance of adhesives. J Dent 1998;26:1-20.

6. Freedman G. The Evolution of Adhesive Techniques. Freedman G. Contemporary Estetic Dentistry. USA; Mosby Elsevier: 2012. s. 168-89.

7. Swift J. Dentin/enamel adhesives: review of the literature. Pediatr Dent 2002;24:456-61

8. Van Meerbeek B, Inoue S, Perdigao J, Lambrechts P, Vanherle G. Enamel and Dentin Adhesion. Summit JB, Robbins JW, Schwartz RS. Fundamentals of Operative dentistry. 2nd ed. Singapore, Quintessence Publishing: 2001. 178235.

9. Anchieta RB, Machado LS, Martini AP, et al. Effect of long-term storage on nanomechanical and morphological properties of dentin-adhesive interfaces. Dent Mater 2015;31:141-53.

10. Kiremitçi $A$, Hürmüzlü $F$. İki Farklı Dentin Adezivin Kompozitleri Dentine Bağlama Dayanıklıı̆ının Karşılaştırıması. Atatürk Üniv Diş Hek Fak Derg 2001;11:34-7.

11. Gupta N, Tripathi AM, Saha S, Dhinsa K, Garg A. Effect of Saliva on the Tensile Bond Strength of Different Generation Adhesive Systems: An InVitro Study. J Clin Diagn Res 2015;9: 91-4.

12. Tyas MJ, Burrow MF. Adhesive restorative materials: a review. Aust Dent J 2004;49:112-21.

13. Abraham S, Ghonmode WN, Saujanya KP, Jaju N, Tambe VH, Yawalikar PP. Effect of grape seed extracts on bond strength of bleached enamel using fifth and seventh generation bonding agents. J Int Oral Health 2013;5:101-7.

14. Hanabusa M, Mine A, Kuboki T, et al. Bonding effectiveness of a new 'multi-mode'adhesive to enamel and dentine. J Dent 2012;40:475-84.

15. Gueders AM, Charpentier JF, Albert AI, Geerts SO. Microleakage after thermocycling of 4 etch and rinse and 3 self-etch adhesives with and without a flowable composite lining. Oper Dent 2006;31:4505.

16. Batra C, Nagpal R, Tyagi SP, Singh UP, Manuja N. In vitro bonding effectiveness of three different one-step self-etch adhesives with additional enamel etching. J Investig Clin Dent 2014;5:22636. 
17. Van Meerbeek B, De Munck J, Yoshida Y, et al. Adhesion to enamel and dentin: current status and future challenges. Oper Dent 2003;28:215-35.

18. Magni E, Radovic I, Coniglio I, Papacchini F, Mazzitelli C, Ferrari M. Bonding of self-etching adhesive/flowable composite combinations to enamel and dentin: a microtensile bond strength evaluation. Dent SA 2007;9:6-18.

19. Perdigao J, Gomes G, Gondo R, Fundingsland JW. In vitro bonding performance of all-in-one adhesives. Part I-microtensile bond strengths. J Adhes Dent 2006;8:367-73.

20. Tay FR, Pashley DH. Have dentin adhesives become too hydrophilic?. J Can Dent Assoc 2003;69:726-32.

21. da Rosa WLDO, Piva E, da Silva AF. Bond strength of universal adhesives: A systematic review and meta-analysis. J Dent 2015;43:765-76.

22. Vaidyanathan TK, Vaidyanathan J. Recent advances in the theory and mechanism of adhesive resin bonding to dentin: a critical review. J Biomed Mater Res B Appl Biomater 2009;88:558-78.

23. Muñoz MA, Luque I, Hass V, Reis A, Loguercio AD, Bombarda NHC. Immediate bonding properties of universal adhesives to dentine. J Dent 2013; 41: 404-11.

24. Küçükeşmen Ç, Erdoğan Y. Süt ve daimi dişlerde bağlayıcı ajanların etkinliği, biyouyumluluğu ve sitotoksisitesi. SDÜ Tıp Fak Derg 2009;16:48-55.

25. Ayaz DF, Tağtekin D, Yanıkoğlu F. Dentine bağlanma ve değerlendirme metodları. Atatürk Üniv Diş Hek Fak 2011;4:49-56.

26. Erickson RL, Barkmeier WW, Latta MA. The role of etching in bonding to enamel: a comparison of self-etching and etch-and-rinse adhesive systems. Dent Mater 2009;25:1459-67.

27. Altun C. Restoratif diş hekimliğinde mikrosızıntı. Gülhane Tıp Derg 2004;46:264-9.

28. Patil BS, Rao BR, Sharathchandra SM, Hegde R, Kumar GV. Comparative Evaluation of Self-etching Primers and Phosphoric Acid Effectiveness on Composite to Enamel Bond: An in vitro Study. J Contemp Dent Pract 2013;14:790-5.

29. Chiang YC, Wang YL, Lin PY, et al. Mesoporous biomaterial for biomimetic crystallization in dentinal tubules without impairing the bonding of a self-etch resin to dentin. J Formos Med Assoc 2016;115:455-62.
30. Oliveira SS, Pugach MK, Hilton JF, Watanabe LG, Marshall SJ, Marshall GW. The influence of the dentin smear layer on adhesion: a self-etching primer vs. a total-etch system. Dent Mater 2003;19:758-67.

31. Frassetto A, Breschi L, Turco G, Marchesi G, Di Lenarda R, Tay FR, Cadenaro M. Mechanisms of degradation of the hybrid layer in adhesive dentistry and therapeutic agents to improve bond durability-A literature review. Dent Mater 2016;32:41-53.

32. Silveira de Araújo C, Incerti da Silva T, Ogliari FA, Meireles SS, Piva E, Demarco FF. Microleakage of seven adhesive systems in enamel and dentin. J Contemp Dent Pract 2006;7:26-33.

33. Swift JEJ, Ritter AV, Heymann HO, Sturdevant JR, Wilder JAD. 36-month clinical evaluation of two adhesives and microhybrid resin composites in Class I restorations. Am J Dent 2008;21:148-52.

34. Pashley DH, Tay FR, Breschi L, et al. State of the art etch-and-rinse adhesives. Dent Mater 2011;27:1-16.

35. Eren D, Bektaş ÖÖ. Dental adezivler. Cumhuriyet Dental Journal 2006;9:63-7.

36. Tay FR, Pashley DH, Kapur RR, et al. Bonding BisGMA to dentin-a proof of concept for hydrophobic dentin bonding. J Dental Res 2007;86:1034-9.

37. Sadek FT, Pashley DH, Nishitani $Y$, et al. Application of hydrophobic resin adhesives to acid-etched dentin with an alternative wet bonding technique. J Biomed Mater Res A 2008;84:19-29.

38. Scheffel DLS, Sacono NT, Ribeiro APD, et al. Immediate human pulp response to ethanol-wet bonding technique. J Dent 2015;43:537-45.

39. Hashimoto M, Nagano F, Endo K, Ohno H. A review: biodegradation of resin-dentin bonds. Jpn Dent Sci 2011;47:5-12.

40. Tjäderhane L, Nascimento FD, Breschi L, et al. Strategies to prevent hydrolytic degradation of the hybrid layer-a review. Dent Mater 2013;29:9991011.

41. De Munck J, Van Meerbeek B, Yoshida Y, et al. Four-year water degradation of total-etch adhesives bonded to dentin. J Dent Res 2003;82:136-40. 
42. Gürpınar ÖA, Beklen A, Hukkanen M, Cehreli ZC, Onur MA, Konttinen YT. Effects of two multi-step self-etch primer/adhesives on apoptosis in human gingival fibroblasts in vitro. J Biomed Mater Res B Appl Biomater 2006;79:435-40.

43. Barutcigil Ç, Barutcigil K, Kürklü D, Harorlı OT. Güncel Dentin Bağlayıcı Ajanların ve Uygulama Yöntemlerinin Makaslama Bağlanma Dayanımlarının Karşılaştırııması. İÜ Sağlık Bilimleri Derg 2013;2:27-32.

44. Reis $A$, de Carvalho Cardoso $P$, Vieira LCC, Baratieri LN, Grande RHM, Loguercio AD. Effect of prolonged application times on the durability of resin-dentin bonds. Dent Mater 2008;24:639-44.

45. Song M, Shin Y, Park JW, Roh BD. A study on the compatibility between one-bottle dentin adhesives and composite resins using micro-shear bond strength. Restor Dent Endod 2015;40:30-6.

46. Sancakli HS, Yildiz E, Bayrak I, Ozel S. Effect of different adhesive strategies on the post-operative sensitivity of class I composite restorations. Eur ] Dent 2014;8:15-22.

47. Hamouda IM, Samra NR, Badawi MF. Microtensile bond strength of etch and rinse versus self-etch adhesive systems. J Mech Behav Biomed Mater 2011;4:461-6.

48. Giannini M, Makishi P, Ayres APA, et al. Self-Etch Adhesive Systems: A Literature Review. Braz Dent J 2015;26:3-10.

49. Wagner A, Wendler M, Petschelt A, Belli R, Lohbauer $U$. Bonding performance of universal adhesives in different etching modes. J Dent 2014;42:800-7.

50. McCabe JF, Walls AWG. Applied Dental Materials. 9th ed. Oxford; Blackwell publishing: 2008. p. 22544.

51. Tay FR, Pashley DH, Garcia-Godoy F, Yiu CK. Single-step, self-etch adhesives behave as permeable membranes after polymerization. Part II. Silver tracer penetration evidence. Am J Dent 2004;17:315-22.

52. Sekhri S, Mittal S, Garg S. Tensile Bond Strength of Self Adhesive Resin Cement After Various Surface Treatment of Enamel J Clin Diagn Res 2016;10:13.

53. Van Landuyt KL, Mine A, De Munck J, et al. Technique sensitivity of water-free one-step adhesives. Dent Mater 2008;24:1258-1267.
54. Carvalho RM, Chersoni S, Frankenberger R, Pashley DH, Prati C, Tay FR. A challenge to the conventional wisdom that simultaneous etching and resin infiltration always occurs in self-etch adhesives. Biomaterials 2005;26:1035-42.

55. Yiu CKY, Garcia-Godoy F, Tay FR, et al. A nanoleakage perspective on bonding to oxidized dentin. J Dent Res 2002;81:628-32.

56. Van Meerbeek B, Yoshihara K, Yoshida Y, Mine A, De Munck J, Van Landuyt KL. State of the art of self-etch adhesives. Dent Mater 2011;27:17-28.

57. Hayakawa T, Kikutake-Sugiyama K, Nemoto K. Efficacy of water-soluble photoinitiator on the adhesion of composite resin to bovine teeth in allin-one bonding system. Dent Mater ] 2005;24:2138.

58. Bağlar S, Bayraktar Y, Ercan E, Mutluay AT, Şengün A. The Challenge of MDP Monomer Contaınıng Adhesıve Systems: Comparıson of Shear Bond Strengths. Atatürk Üniv Diş Hek Fak 2015;25:21-8.

59. Tsuchiya K, Takamizawa T, Barkmeier WW, et al. Effect of a functional monomer (MDP) on the enamel bond durability of single-step self-etch adhesives. Eur J Oral Sci 2015;124:96-102.

60. Yoshida Y, Yoshihara K, Nagaoka N, et al. Selfassembled nano-layering at the adhesive interface. J Dent Res 2012;91:376-81.

61. Yoshida Y, Van Meerbeek B, Nakayama Y, et al. Adhesion to and decalcification of hydroxyapatite by carboxylic acids. J Dent Res 2001;80:1565-9.

62. Dieng-Sarr F, Sharrock P, Dabsie F, Grégoire G. Modifications of the organic and mineral fractions of dental tissues following conditioning by selfetching adhesives. J Dent 2011;39:141-7.

63. Imazato S, Kinomoto Y, Tarumi H, Ebisu S, Tay FR. Antibacterial activity and bonding characteristics of an adhesive resin containing antibacterial monomer MDPB. Dent Mater 2003;19:313-9.

64. Imazato S, Ehara A, Torii M, Ebisu S. Antibacterial activity of dentine primer containing MDPB after curing. J Dent 1998;26:267-71.

65. Atram H, Jakati SV, Aley M, Chachada A, Mankar M. Clearfil Protect Bond ${ }^{\mathrm{TM}}$ versus Uni-Etch ${ }^{\mathrm{TM}}$ antibacterial self-etchant: A war of giants against shear bond strength. Indian J Dent Res 2016;27:54-60. 
66. Reis A, Moura SK, Pellizzaro A, et al. Durability of enamel bonding using one-step self-etch systems on ground and unground enamel. Oper Dent 2009;34:181-91.

67. Ito $S$, Tay FR, Hashimoto $M$, et al. Effects of multiple coatings of two all-in-one adhesives on dentin bonding. J Adhes Dent 2005;7:133-41.

68. Chopra V, Sharma H, Prasad SDA . Comparative evaluation of the bonding efficacy of two-step vs all-in-one bonding agents-An in-vitro study. J Conserv Dent 2009;12:101-4.

69. Takamizawa T, Barkmeier WW, Tsujimoto A, et al. Influence of water storage on fatigue strength of self-etch adhesives. J Dent 2015;43:1416-27.

70. Lührs AK, Guhr S, Schilke R, Borchers L, Geurtsen $W$, Günay $H$. Shear bond strength of self-etch adhesives to enamel with additional phosphoric acid etching. Oper Dent 2008;33:155-62.

71. Camelia ALB, Fodor O, Ioan TIG, et al. Tensile Bond Strength of Four Adhesive Systems. Bulletin of University of Agricultural Sciences and Veterinary Medicine Cluj-Napoca. Veterinary Medicine 2009;66:188-95.

72. Tekçe N, Özsoy A, Bağ HG. Yüzey dehidratasyonunun (Etanol Wet Bonding) günümüz iki adet self etch adeziv sistemin mikrosızıntı skorlarına etkisi. CBU-SBED 2013;4:95-103.

73. Tay FR, Pashley DH. Have dentin adhesives become too hydrophilic?. J Can Dent Assoc 2003;69:726-32.

74. Chen $\mathrm{C}$, Niu LN, Xie $\mathrm{H}$, et al. Bonding of universal adhesives to dentine-Old wine in new bottles?. J Dent 2015;43:525-36.

75. Perdigão J, Swift EJ. Universal Adhesives. J Esthet Restor Dent 2015;27:331-4.

76. Zhang ZY, Tian FC, Niu LN, et al. Defying ageing: An expectation for dentine bonding with universal adhesives?. J Dent 2016;45:43-52.

77. Eren D, Bektaş ÖÖ. Dental adezivler. Cumhuriyet Dental Journal 2006;9:63-7.

78. Inoue $S$, Van Meerbeek $B$, Abe $Y$, et al. Effect of remaining dentin thickness and the use of conditioner on micro-tensile bond strength of a glass-ionomer adhesive. Dent Mater 2001;17:44555.

79. Tyas MJ, Burrow MF. Adhesive restorative materials: a review. Aust Dent J 2004;49:112-21.

\section{Yazışma Adresi}

Buket AYNA

Dicle Üniversitesi, Diş Hekimliği Fakültesi, Çocuk Diş Hekimliği AD. Diyarbakır.

Tel: 00904122488101-06

Fax: 00904122488100

E-Mail: buketayna@hotmail.com 